\title{
How Cohabitation, Marriage, Separation, and Divorce Influence BMI: A Prospective Panel Study
}

\author{
Jutta Mata \\ University of Mannheim and Max Planck Institute for Human \\ Development, Berlin, Germany
}

\author{
David Richter \\ German Institute for Economic Research (DIW Berlin), \\ Berlin, Germany \\ Ralph Hertwig \\ Max Planck Institute for Human Development, Berlin, Germany
}

\begin{abstract}
Objective: This study examines how changes in cohabitation or marital status affect Body Mass Index (BMI) over time in a large representative sample. Method: Participants were 20,950 individuals (50\% female; 19 to 100 years), representative of the German population, who provided 81,926 observations over 16 years. Face-to-face interviews were used to obtain demographic data, including cohabitation and marital status, height, body weight, and weight-relevant behaviors (exercise, healthy eating, and smoking). Control variables included age, notable changes in status (life events such as having children or change in employment status), perceived stress, and subjective health. Results: Cohabitation led to significant weight gain in men and women - after four years or longer, about twice the gain associated with marriage (controlling for weight-related behaviors, age, children, employment, stress, and health). BMI after separation was largely comparable to BMI before starting cohabitation; women lost some weight in the first year, men gained some weight after four or more years of separation. Divorce generally predicted weight gain. Changes in exercise, healthy eating, and smoking did not attenuate the effect of changes in relationship status on BMI. Conclusions: This is among the first longitudinal studies to directly compare the effects of key changes in relationship status on BMI. The findings extend and qualify previous results by showing that the benefits of marriage or cohabitation do not necessarily include a healthier BMI. They also suggest that relationship transitions-particularly moving in with a partner and divorce-may be important time windows for weight gain prevention.

Keywords: obesity, relationship, relationship transition, health, longitudinal

Supplemental materials: http://dx.doi.org/10.1037/hea0000654.supp
\end{abstract}

Social relationships influence body weight and obesity (Christakis \& Fowler, 2007). Two major relationship transitions that most adults experience are moving in with a partner and getting married (Kreider \& Ellis, 2011). Several longitudinal studies suggest that particularly getting married (e.g., Gallo, Troxel, Matthews, \& Kuller, 2003; Kiecolt-Glaser \& Newton, 2001), but also starting to cohabit (Kohn \& Averett, 2014; Musick \& Bumpass, 2012), is beneficial for general health. In contrast, separating from a partner

Jutta Mata, Department of Social Sciences, University of Mannheim, and Max Planck Institute for Human Development, Berlin, Germany; David Richter, German Institute for Economic Research (DIW Berlin), Berlin, Germany; Thorsten Schneider, Institute of Sociology, University of Leipzig; Ralph Hertwig, Center for Adaptive Rationality, Max Planck Institute for Human Development.

We are grateful to Susannah Goss, Lena Haas, Petra Kühner-Knaup, Emelie Letzsch, and Nicole Engelhardt.

Correspondence concerning this article should be addressed to Jutta Mata, Department of Social Sciences, University of Mannheim, L13, 17, 68131 Mannheim, Germany. E-mail: mata@uni-mannheim.de or divorcing has detrimental health effects (e.g., Sbarra, Law, \& Portley, 2011). However, less is known about how these relationship transitions affect body weight, an important indicator of general health.

According to the marriage market hypothesis, individuals who are no longer on the marriage market, and thus no longer concerned with attracting a mate, gain weight (e.g., Meltzer, Novak, McNulty, Butler, \& Karney, 2013). Following the same logic, divorcees strive to lose weight when they reenter the marriage market (Averett, Sikora, \& Argys, 2008; Lundborg, Nystedt, \& Lindgren, 2007). This hypothesis makes no explicit predictions about the effects of starting or ending cohabitation. Some authors suggest that cohabitation has similar effects on health as marriage (Kohn \& Averett, 2014; Musick \& Bumpass, 2012); others suggest qualitatively different effects (e.g., Marcussen, 2005).

Most empirical studies on the relation between marital transitions and BMI support the marriage market hypothesis. A review of longitudinal studies examining marital transitions and changes in BMI (Dinour, Leung, Tripicchio, Khan, \& Yeh, 2012) found that six of 13 studies reported weight increases for both genders after marriage, five reported increases for one gender only, and 
two reported no weight change. Three of four studies examining weight changes after starting cohabitation showed increased risks of weight gain. Findings for weight changes after divorce were mixed: Two of 12 studies reported weight loss in both genders, eight reported weight loss in one gender, and two reported no weight change. Only one study has examined the effects of ending cohabitation (in a male sample); its findings showed weight loss (Fogelholm, Kujala, Kaprio, \& Sarna, 2000). Studies published since the 2012 review by Dinour et al. largely confirm the previous findings (Averett, Argys, \& Sorkin, 2013; Oliveira, Rostila, de Leon, \& Lopes, 2013).

The marriage market hypothesis does not specify the mechanisms that lead to increases in BMI when couples move in together or get married. One potential underlying mechanism is a change in weight-related behaviors. For example, the negative-protection explanation proposes that marriage (and potentially cohabitation) entails reciprocal spousal obligations such as regular family meals (Sobal \& Rauschenbach, 2003) and more frequent meals in company. Eating in company is associated with consuming more calories than is eating alone (Herman, 2015). In addition, the poor eating habits of one spouse can migrate to the other (Hartmann, Dohle, \& Siegrist, 2014). Lastly, married individuals exercise less than those who have never married (Mata, Frank, \& Hertwig, 2015; Rapp \& Schneider, 2013).

In contrast, the marriage-protection explanation proposes that marriage (or cohabitation) is advantageous for a healthy weight: Spouses can monitor and encourage each other to eat healthily or be physically active (Khan, Stephens, Franks, Rook, \& Salem, 2013). They also spend more time on cooking than singles or unmarried couples, which is associated with a healthier diet (Monsivais, Aggarwal, \& Drewnowski, 2014). Married couples tend to have more financial resources (Averett et al., 2008) and are thus better able to afford a healthier lifestyle. People in a relationship are also more likely to stop smoking if their partner does not smoke (Klein, Rapp, \& Schneider, 2013). However, smoking cessation increases the chance of weight gain (Aubin, Farley, Lycett, Lahmek, \& Aveyard, 2012).

This study examines the influence of changes in cohabitation and marital status on the development of BMI over 16 years, considering the potential role of weight-related behaviors. It contributes to existing research in at least four important ways: (1) It is the first study to explicitly compare long-term effects of key relationship transitions-cohabitation, marriage, separation, and divorce- on BMI. Further, research into how separation and divorce affect BMI is lacking. (2) The panel data used in this study come from Germany. To date, few relevant studies have been conducted outside the United States. (3) Few longitudinal studies have considered the potential role of weight-related behaviors (but see Oliveira et al., 2013, who controlled for physical activity). To help fill this gap, this study investigates to what extent exercise, healthy eating, and smoking can help explain weight changes after relationship transitions. (4) Finally, this study controls for important influences on BMI that have often been ignored in previous research, including life events such as having children, changes in employment status, perceived stress, and health issues (Dinour et al., 2012).

Based on the marriage market hypothesis, the following predictions were formulated for both men and women: (1) starting to cohabit or getting married leads to weight gain; (2) weight gain is more pronounced after getting married than after starting to cohabit; (3) separating or getting divorced leads to weight loss; (4) weight loss is more pronounced after divorce than after separation. Hypotheses 5 and 6 make contrasting predictions about behavioral changes that could affect BMI: (5) Changes in BMI after starting to cohabit or getting married are at least partly explained by exercising less, eating less healthily, or smoking more than when single (negative protection hypothesis) versus (6) changes in BMI after starting to cohabit or getting married are at least partly explained by exercising more, eating more healthily, or smoking less than when single (marriage protection hypothesis). The present analyses test whether one of these two hypotheses is supported by the data. Given the scarcity of work on the effects of ending cohabitation or getting divorced on changes in weight-related behaviors, no specific hypotheses are proposed for these transitions. Sex differences in the effects of relationship transitions on BMI and effects of weight-related behaviors are explored.

\section{Method}

\section{Data}

The data were drawn from the German Socio-Economic Panel (SOEP; Version 31; German Institute for Economic Research), an ongoing, nationally representative longitudinal study of private households in Germany initiated in 1984 with several refreshment samples thereafter. Comprehensive information about design, participants, and measures is reported in Wagner, Frick, and Schupp (2007). All participants provided informed consent; the Institutional Review Board of the German Institute for Economic Research approved the study.

The data analyzed in the present study were collected over 16 years (1998 to 2014, subsamples A to $H$; later subsamples lack relevant information on relationship status). The total sample comprised 31,831 adults living in Germany. Respondents were excluded if they did not provide any valid body weight assessments ( $n=1053)$ or provided fewer than five years of observations $(n=$ $4,522)$; respondents who were widowed $(n=2,563)$ or remarried ( $n=4,095)$ were excluded to avoid confounding effects of previous marriages. Importantly, the sum of excluded and included respondents is higher than the total sample, because excluded participants can simultaneously belong to more than one category (e.g., be widowed and not report body weight). Observations of participants who remarried or became widowed during the study period were included up to this relationship transition. The remaining sample consisted of 20,950 individuals providing 81,926 observations. The original sample was comparable to the final sample with regard to the variables of interest (see Table S1 in the online supplementary material). Over the entire study period, the drop-out rate was $10.8 \%$ (based on observations). Continuers differed minimally from drop-outs (as tested using data from the last available observation) in that drop-outs paid less attention to healthy eating (Cohen's $d=0.07)$, exercised less $(d=0.17)$, and were older $(d=$ 0.12 ). There were no significant differences in smoking, gender, or BMI. General information on drop-out rate and refreshment sampling in the Socio-Economic Panel can be found in Kroh, Kühne, and Siegers (2017).

Only relationship transitions experienced for the first time over the study period were included in the models. For example, if a 
participant started to cohabit, got married, separated, and then divorced, all of those transitions would be included. If she then remarried, her data after remarriage would be excluded to avoid confounding the effects of this remarriage with the influence of all previous relationship transitions on BMI (see Table 1 for a transition coding scheme). One exception was made to avoid losing a significant proportion of the sample: The reference category (i.e., not cohabiting) for estimating the effects of cohabitation status was defined as including both respondents who had never lived with a partner and respondents who had not done so in the past four years. Importantly, including the latter group makes the estimate of cohabitation effects on weight change more conservative.

Marital and fertility history data from a retrospective life course questionnaire, administered at the start of SOEP participation and updated yearly, were combined with additional data from the 1998 to 2001 surveys to build indices of relationship status and childbirth. Respondents were interviewed every year. Employment was assessed yearly; body weight, height, perceived stress, and subjective health were assessed biennially starting in 2002. Weight-related behaviors were measured biennially; exercise since 2001, smoking since 2002, and healthy eating since 2004. Yearly estimates for effects of relationship status and weight-related behaviors on BMI can be reported because some participants had moved, for example, from no relationship to the first year of a relationship when BMI was assessed; others had moved to the second year. The personspecific effects after the first, second, third, and so forth, year of a relationship transition on BMI were averaged over all valid observations.

\section{Measures}

Body weight and height were self-reported by respondents. To reduce measurement error, body weight was treated as missing if it deviated from the respondent's median body weight by a factor greater than 1.5 or lower than 0.66 . Consequently, 86 observations were deleted. If the reported height in centimeters was below 100, 100 was added $(n=3$ observations). If participants reported different heights over time, the median was taken $(29.6 \%$ of observations; mean variation $=$ $2.17 \mathrm{~cm} ; 75 \%$ of this subsample varied by $\leq 2 \mathrm{~cm}$ ). Importantly, for participants with varying height reports, all BMI values were calculated with the same median height; BMI was thus not influenced by this variation. Moreover, the results of analyses excluding all participants with varying height reports were comparable with those reported here.

Duration of cohabitation or marriage/time since separation or divorce were determined by reference to both (a) the life course questionnaire administered to participants entering the SOEP, and (b) three questions administered every year: First, respondents were asked to state their marital status. Second, respondents who were unmarried or permanently separated from their spouse were asked whether they were in a committed relationship. Third, individuals in a committed relationship were asked whether their partner lived in the same household (see Table 1 for coding details). Same-sex couples in cohabitation or civil union (coded as married) are included; however, they represent only $0.04 \%$ of all observations in this study.

Weight-related behaviors were assessed by three questions: "How often do you exercise?" with responses on a 4-point scale ("daily" to "never"); "How much attention do you pay to healthy eating?" (4-point scale "very much" to "none at all"); "Do you currently smoke cigarettes, a pipe, or cigars?" (response options "yes" and "no").

Control variables. Age was calculated based on the birth date. The child-related events pregnancy, recent birth, and having children were assessed and coded as follows: if a child was born (a) up to eight months after an interview, pregnancy was coded "1"; (b) up to 18 months before an interview, recent birth was coded "1"; (c) more than 18 months before an interview, having children was coded "1." These three predictors were mutually exclusive; priority was given to the most recent child-related event. Employment status was assessed by the question "Are you currently employed? Which of the following best describes your status?" The response options "employed full-time," "voluntary military service," and "voluntary social year" were coded as fulltime employment. "Employed part-time," "completing in-service (re-) training," and "marginal or irregular employment" were coded as part-time employment. Attending school or university and "not employed" were coded as "not working." Perceived stress was measured by the question "During the last weeks, how often did you feel rushed or pressed for time?" (5-point scale "always" to "never"); subjective health by the question "How

Table 1

Coding Scheme for the Dummy Variables for Duration of Cohabitation, Separation, Marriage and Divorce

\begin{tabular}{ccccccccccccccccccc}
\hline Measurement & Cohabitation & Marital status & $\mathrm{c} 1$ & $\mathrm{c} 2$ & $\mathrm{c} 3$ & $\mathrm{c} 4+$ & $\mathrm{s} 1$ & $\mathrm{~s} 2$ & $\mathrm{~s} 3$ & $\mathrm{~s} 4$ & $\mathrm{~m} 1$ & $\mathrm{~m} 2$ & $\mathrm{~m} 3$ & $\mathrm{~m} 4+$ & $\mathrm{d} 1$ & $\mathrm{~d} 2$ & $\mathrm{~d} 3$ & $\mathrm{~d} 4+$ \\
\hline 1 & no & single & 0 & 0 & 0 & 0 & 0 & 0 & 0 & 0 & 0 & 0 & 0 & 0 & 0 & 0 & 0 & 0 \\
2 & yes & single & $\mathbf{1}$ & 0 & 0 & 0 & 0 & 0 & 0 & 0 & 0 & 0 & 0 & 0 & 0 & 0 & 0 & 0 \\
3 & yes & single & 0 & $\mathbf{1}$ & 0 & 0 & 0 & 0 & 0 & 0 & 0 & 0 & 0 & 0 & 0 & 0 & 0 & 0 \\
4 & yes & married & 0 & 0 & $\mathbf{1}$ & 0 & 0 & 0 & 0 & 0 & $\mathbf{1}$ & 0 & 0 & 0 & 0 & 0 & 0 & 0 \\
5 & yes & married & 0 & 0 & 0 & $\mathbf{1}$ & 0 & 0 & 0 & 0 & 0 & $\mathbf{1}$ & 0 & 0 & 0 & 0 & 0 & 0 \\
6 & yes & married & 0 & 0 & 0 & $\mathbf{1}$ & 0 & 0 & 0 & 0 & 0 & 0 & $\mathbf{1}$ & 0 & 0 & 0 & 0 & 0 \\
7 & no & married & 0 & 0 & 0 & 0 & $\mathbf{1}$ & 0 & 0 & 0 & 0 & 0 & 0 & $\mathbf{1}$ & 0 & 0 & 0 & 0 \\
8 & no & married & 0 & 0 & 0 & 0 & 0 & $\mathbf{1}$ & 0 & 0 & 0 & 0 & 0 & $\mathbf{1}$ & 0 & 0 & 0 & 0 \\
9 & no & married & 0 & 0 & 0 & 0 & 0 & 0 & $\mathbf{1}$ & 0 & 0 & 0 & 0 & $\mathbf{1}$ & 0 & 0 & 0 & 0 \\
10 & no & divorced & 0 & 0 & 0 & 0 & 0 & 0 & 0 & $\mathbf{1}$ & 0 & 0 & 0 & 0 & $\mathbf{1}$ & 0 & 0 & 0 \\
\hline
\end{tabular}

Note. $\mathrm{c} 1$ to $\mathrm{c} 4+=$ Cohabiting in the first, second, third, or fourth year; $\mathrm{s} 1$ to $\mathrm{s} 4=$ separated in the first, second, third or fourth year; $\mathrm{m} 1$ to $\mathrm{m} 4+=\mathrm{married}$ in the first, second, third, fourth or more years; $\mathrm{d} 1$ to $\mathrm{d} 4+=$ divorced in the first, second, third, fourth or more years. 
would you describe your current health?" (5-point scale "very good" to "bad").

\section{Statistical Analyses}

As the data are nested within the same person, a multilevel framework was employed (Raudenbush, \& Bryk, 2002). Within-person variation was modeled to estimate the impact of relationship transitions on BMI, that is, each person was compared with him- or herself before and after relationship transitions. This approach has the advantage that the results are not confounded by time-constant unobserved heterogeneity (e.g., social origin). The influence on within-person change (i.e., change in BMI) can be modeled only if change in this variable is observed. Only 946 persons in the entire sample, that is, $3 \%$ of all observations, did not report any change in BMI; these respondents were excluded from the analyses. When these 946 persons were assigned an artificial within-person change in BMI (i.e., a mean of 0.0 and a $S D$ of 0.0001 ) and included in the analyses, the results were identical with those of the sample reporting a change in BMI (results not shown). Given the high variability in the outcome variable BMI, the within-person modeling approach is adequate. The data were analyzed by estimating the following model: $Y_{i t}=X_{i t} \hat{\beta}+$ $D_{i} \hat{\gamma}+\varepsilon_{i t}$, where the dependent variable $Y_{i t}$ is the BMI of person $i$ at time $t ; X_{i t}$ indicates the matrix of covariates containing values on the current situation of person $i$ (e.g., whether they experienced a transition such as getting married); $\hat{\beta}$ represents the vector of the regression weights; $D_{i}$ is a matrix containing dummy variables for every single person; and the vector $\hat{\gamma}$ refers to the estimation of every person's mean BMI. $\varepsilon_{i t}$ is the error term (Bruederl \& Ludwig, 2015). As there were several observations per person, standard errors were corrected using a clustered sandwich estimator. Analyses were conducted in Stata Version 12, using the areg command.

Analyses were conducted separately for men (see Table 3) and women (see Table 4) because BMI is a more important indicator of attractiveness in women (Weeden \& Sabini, 2005 for a review). Further, effects of pregnancy on body weight differ between men and women (Brennan, Ayers, Ahmed, \& Marshall-Lucette, 2007), and women pay more attention to their nutrition (Kiefer, Rathmanner, \& Kunze, 2005), but exercise less (Mata et al., 2015; Rapp \& Schneider, 2013). Additional tests of how sex differences in relationship transitions affected BMI are reported in Table 2.

Six models were calculated (see Tables 3 and 4), each model building on the previous one by adding new variables: Model 1a estimates the effects of changes in marital status on BMI; Model 1b estimates the effect of changes of cohabitation status on BMI. Separate analyses were conducted for changes in marital versus cohabitation status because cohabitation can be less stable and have different health consequences than marriage (Horwitz \& White, 1998). Model 2a estimates the effects of changes in both marital and cohabitation status. Including changes in marital and cohabitation status in the same model makes it possible to estimate the effect of one while controlling for the other. For example, by comparing the beta values of Model 2a with Model 1a, one can determine the influence of getting married on BMI, controlling for cohabitation (Model 2a shows the "net" influence of changes in marital status on BMI, independent of any premarriage effects of cohabitation), relative to the influence of getting married on BMI, not controlling for cohabitation (Model 1a). Model 3 additionally includes weight-related behaviors as predictors. As these data are available for only a subsample of participants,

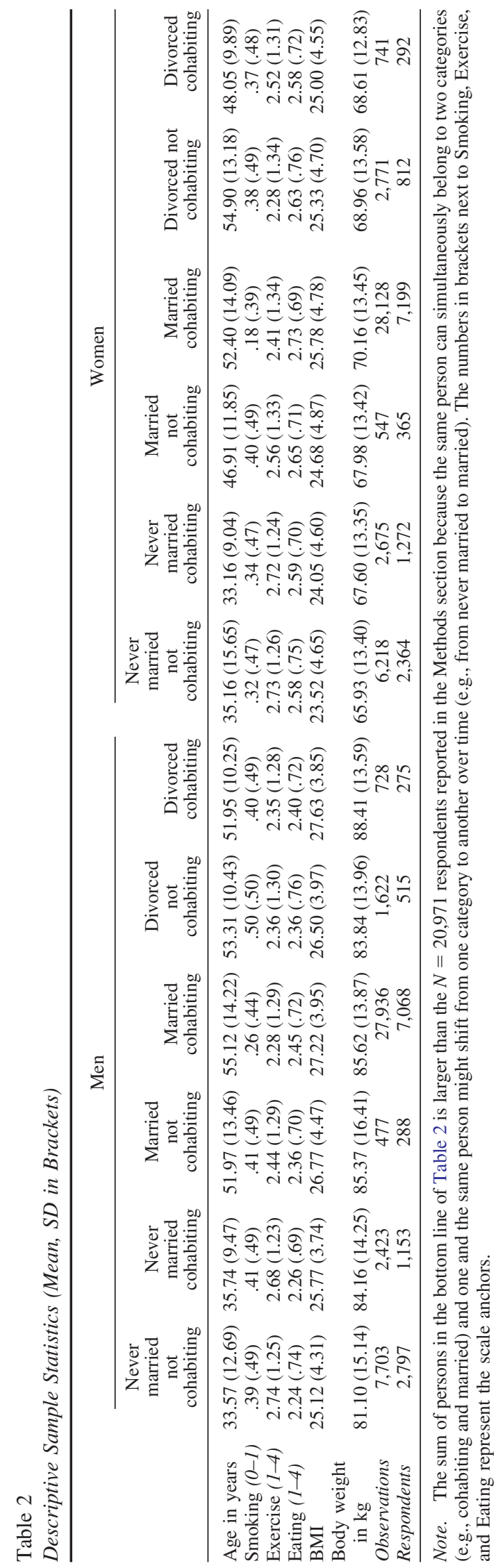


Table 3

Estimates Predicting Body Mass Index in Men (Unadjusted Betas)

\begin{tabular}{|c|c|c|c|c|c|c|}
\hline & $\begin{array}{l}\text { Model 1a: } \\
\text { marital status }\end{array}$ & $\begin{array}{l}\text { Model 1b: } \\
\text { cohabitation } \\
\quad \text { status }\end{array}$ & $\begin{array}{l}\text { Model 2a: } \\
\text { marital and } \\
\text { cohabitation } \\
\text { status, all } \\
\text { participants }\end{array}$ & $\begin{array}{l}\text { Model 2b: } \\
\text { marital and } \\
\text { cohabitation } \\
\text { status, } \\
\text { participants } \\
\text { reporting weight- } \\
\text { related behaviors }\end{array}$ & $\begin{array}{c}\text { Model 3: } \\
\text { marital and } \\
\text { cohabitation } \\
\text { status, weight- } \\
\text { related } \\
\text { behaviors }\end{array}$ & $\begin{array}{c}\text { Model 4: } \\
\text { marital and } \\
\text { cohabitation } \\
\text { status, weight- } \\
\text { related } \\
\text { behaviors, } \\
\text { control } \\
\text { variables }\end{array}$ \\
\hline Age & $.073^{* * * * *}(.002)$ & $.078^{* * * *}(.002)$ & $.072^{* * * *}(.002)$ & $.073^{* * * *}(.003)$ & $.071^{* * * *}(.003)$ & $.071^{* * * * *}(.003)$ \\
\hline Age-squared & $-.006^{* * * *}(.001)$ & $-.006^{* * * *}(.001)$ & $-.005^{* * * * *}(.001)$ & $-.006^{* * *}(.001)$ & $-.006^{* * * *}(.001)$ & $-.006^{* * * *}(.001)$ \\
\hline \multicolumn{7}{|l|}{$\begin{array}{l}\text { Marital status (reference: BMI } \\
\text { before first marriage) }\end{array}$} \\
\hline Married, first year & $.532^{* * * * *}(.089)$ & & $.291^{* *}(.092)$ & $.298^{* * *}(.100)$ & $.303^{* * *}(.100)$ & $.255^{*}(.101)$ \\
\hline Married, second year & $.566^{* * * *}(.091)$ & & $.263^{* * *}(.095)$ & $.222^{*}(.103)$ & $.215^{*}(.102)$ & $.138(.105)$ \\
\hline Married, third year & $.629^{* * * *}(.093)$ & & $.289^{* *}(.098)$ & $.322^{* * *}(.108)$ & $.317^{* * *}(.107)$ & $.224^{*}(.110)$ \\
\hline Married, four or more years & $.833^{* * * *}(.069)$ & & $.509^{* * * * *}(.077)$ & $.478^{* * * * *}(.086)$ & $.466^{* * * * *}(.086)$ & $.325^{* * * *}(.093)$ \\
\hline Divorced, first year & $.683^{* * * *}(.154)$ & & $.679^{* * * *}(.155)$ & $.685^{* * * *}(.173)$ & $.688^{* * * *}(.172)$ & $.557^{* *}(.175)$ \\
\hline Divorced, second year & $1.049^{* * * *}(.158)$ & & $.977^{* * * *}(.160)$ & $.990^{* * * *}(.175)$ & $.979^{* * * *}(.175)$ & $.840^{* * * *}(.178)$ \\
\hline Divorced, third year & $.971^{* * * * *}(.163)$ & & $.919^{* * * * *}(.164)$ & $.975^{* * * * *}(.179)$ & $.946^{* * * * *}(.179)$ & $.803^{* * * * *}(.182)$ \\
\hline $\begin{array}{l}\text { Divorced, four or more } \\
\text { years }\end{array}$ & $1.222^{* * * *}(.118)$ & & $1.163^{* * * *}(.119)$ & $1.198^{* * * *}(.137)$ & $1.191^{\text {***** }}(.137)$ & $1.056^{* * * *}(.140)$ \\
\hline \multicolumn{7}{|l|}{$\begin{array}{l}\text { Cohabitation (reference: BMI } \\
\text { when living without a } \\
\text { partner) }\end{array}$} \\
\hline Cohabiting, first year & & $.282^{* * * *}(.078)$ & $.299^{* * * * *}(.080)$ & $.291^{* *}(.089)$ & $.307^{* * * * *}(.089)$ & $.289^{* *}(.089)$ \\
\hline Cohabiting, second year & & $.534^{* * * *}(.078)$ & $.535^{* * * *}(.080)$ & $.512^{* * * * *}(.086)$ & $.518^{* * * * *}(.086)$ & $.484^{* * * *}(.087)$ \\
\hline Cohabiting, third year & & $.624^{* * * *}(.090)$ & $.636^{* * * *}(.094)$ & $.648^{* * * *}(.102)$ & $.627^{* * * *}(.102)$ & $.586^{* * * *}(.103)$ \\
\hline \multicolumn{7}{|l|}{ Cohabiting, four or more } \\
\hline years & & $.795^{* * * *}(.059)$ & $.723^{* * * *}(.068)$ & $.760^{* * * *}(.075)$ & $.745^{* * * * *}(.074)$ & $.685^{* * * *}(.076)$ \\
\hline Separated, one year & & $-.172(.090)$ & $-.126(.093)$ & $-.102(.103)$ & $-.092(.103)$ & $-.116(.103)$ \\
\hline Separated, two years & & $.128(.102)$ & $.150(.105)$ & $.207(.112)$ & $.220 *(.112)$ & $.183(.112)$ \\
\hline Separated, three years & & $-.029(.100)$ & $-.014(.102)$ & $.010(.111)$ & $.023(.110)$ & $-.004(.111)$ \\
\hline Separated, four years & & $.229^{*}(.111)$ & $.209(.114)$ & $.283^{*}(.120)$ & $.289^{*}(.120)$ & $.264^{*}(.120)$ \\
\hline \multicolumn{7}{|l|}{ Weight-related behaviors } \\
\hline Smoking $(1=$ yes $)$ & & & & & $-.312^{* * * * *}(.038)$ & $-.311^{* * * *}(.038)$ \\
\hline Exercise & & & & & $-.046^{* * * *}(.010)$ & $-.043^{* * * *}(.010)$ \\
\hline Eating & & & & & $-.167^{* * * * *}(.017)$ & $-.164^{* * * *}(.017)$ \\
\hline \multicolumn{7}{|l|}{ Control variables } \\
\hline Partner pregnant $(1=$ yes $)$ & & & & & & $.247^{*}(.106)$ \\
\hline Recent birth $(1=$ yes $)$ & & & & & & $.270^{* *}(.092)$ \\
\hline Having children $(1=$ yes $)$ & & $.358^{* * * *}(.095)$ \\
\hline \multicolumn{7}{|l|}{ from not working to } \\
\hline$(1=$ yes $)$ & & & & & & $.128^{* * * * *}(.037)$ \\
\hline $\begin{array}{l}\text { Employment: Transition } \\
\text { from not working to } \\
\text { working part-time }\end{array}$ & & & & & & \\
\hline$(1=$ yes $)$ & & & & & & $.077(.047)$ \\
\hline Stress & & & & & & $-.020(.012)$ \\
\hline Health & & & & & & $-.024(.014)$ \\
\hline Constant & $26.125^{* * * * *}(.051)$ & $26.170^{* * * *}(.046)$ & $25.810^{* * * * * *}(.060)$ & $25.828^{* * * * *}(.068)$ & $26.449^{* * * * *}(.083)$ & $26.434^{* * * * *}(.104)$ \\
\hline Observations & 40,867 & 40,867 & 40,867 & 35,496 & 35,496 & 35,423 \\
\hline
\end{tabular}

Note. Table 3 can be read as follows: To differentiate the effects of changes in marital versus cohabitation status, Model 1a (which includes only changes in marital status), Model $1 \mathrm{~b}$ (only changes in cohabitation status), and Model $2 \mathrm{a}$ are presented next to each other. Including changes in cohabitation and marital status in the same model makes it possible to estimate the effect of one while controlling for the other. For example, by comparing the beta values of Model 1a with Model 2a, one can see that the influence of getting married on BMI is roughly halved when the effects of cohabitation are controlled (as is done in Model 2a). However, the effects of moving in together on BMI stay about the same when the effects of getting married are controlled. Importantly, Model 2a includes all participants, whereas Model $2 b$ includes only participants for whom smoking, exercise, and eating were assessed. Due to the lower number of cases, only the results of Model $2 \mathrm{~b}$ can be directly compared with the results of Models 3 and 4 . Please note that despite diverging case numbers, Models 2a and 2b yield comparable results. Analogous comparisons can be made with Models 3 and 4. Model 3 includes weight-related behaviors. Here, a negative beta shows that starting to smoke resulted in a lower BMI, to quit smoking lead to a higher BMI. Model 4 includes the control variables (i.e., children, change in employment status, stress, and health). BMI before first marriage is used as the reference BMI for the effects of both marriage and divorce on BMI. The same reference is used to make the effects of marriage and divorce comparable. However, the beta weights in Table 3 can be used to understand whether divorce leads to weight loss relative to post-marriage BMI (i.e., being married for four years or more): The beta-weight of "divorced, four or more years" (e.g., from Model 4) minus the beta-weight of "married, four or more years" shows the weight change; here, 1.056 $.325=.731$. The value is positive; this means that men have gained weight (increased their BMI by $.731 \mathrm{~kg} / \mathrm{m}^{2}$ ) after a divorce relative to their BMI after four years or more of being married. If the value was negative, they would have lost weight; if the value was zero, their weight would not have changed. Standard errors in parentheses. BMI = body mass index.

${ }^{*} p<.05 .{ }^{* * *} p<.01 .{ }^{* * * *} p<.001$. 
Table 4

Estimates Predicting Body Mass Index in Women (Unadjusted Betas)

\begin{tabular}{|c|c|c|c|c|c|c|}
\hline & $\begin{array}{l}\text { Model 1a: } \\
\text { marital status }\end{array}$ & $\begin{array}{l}\text { Model 1b: } \\
\text { cohabitation } \\
\text { status }\end{array}$ & $\begin{array}{l}\text { Model 2a: } \\
\text { marital and } \\
\text { cohabitation } \\
\text { status, all } \\
\text { participants }\end{array}$ & $\begin{array}{l}\text { Model 2b: } \\
\text { marital and } \\
\text { cohabitation } \\
\text { status, } \\
\text { participants with } \\
\text { weight behaviors }\end{array}$ & $\begin{array}{l}\text { Model 3: } \\
\text { marital and } \\
\text { cohabitation } \\
\text { status, weight } \\
\text { behaviors }\end{array}$ & $\begin{array}{c}\text { Model 4: } \\
\text { marital and } \\
\text { cohabitation } \\
\text { status, weight } \\
\text { behaviors, } \\
\text { control } \\
\text { variables }\end{array}$ \\
\hline Age & $.088^{* * * * *}(.003)$ & $.093^{* * * * *}(.002)$ & $.088^{* * * *}(.003)$ & $.087^{* * * *}(.003)$ & $.086^{* * * *}(.003)$ & $.085^{* * * *}(.003)$ \\
\hline Age-squared & $-.006^{* * * *}(.001)$ & $-.006^{* * * *}(.001)$ & $-.006^{* * * *}(.001)$ & $-.006^{* * * *}(.001)$ & $-.006^{* * * *}(.001)$ & $-.006^{* * * *}(.001)$ \\
\hline \multicolumn{7}{|l|}{$\begin{array}{l}\text { Marital status (reference: BMI } \\
\text { before first marriage) }\end{array}$} \\
\hline Married, first year & $.737^{* * * *}(.096)$ & & $.506^{* * * *}(.098)$ & $.602^{* * * *}(.105)$ & $.546^{* * * * *}(.105)$ & $.330^{* * *}(.106)$ \\
\hline Married, second year & $.519^{* * * *}(.098)$ & & $.274^{* *}(.102)$ & $.338^{* * *}(.109)$ & $.287^{* * *}(.109)$ & $.086(.111)$ \\
\hline Married, third year & $.762^{* * * *}(.099)$ & & $.461^{* * * *}(.104)$ & $.447^{* * * *}(.112)$ & $.398^{* * * *}(.112)$ & $.171(.115)$ \\
\hline Married, four or more years & $.690^{* * * *}(.073)$ & & $.419^{* * * *}(.082)$ & $.451^{* * * *}(.090)$ & $.407^{* * * * *}(.090)$ & $.220^{*}(.096)$ \\
\hline Divorced, first year & $.543^{* * * *}(.151)$ & & $.654^{* * * * *}(.155)$ & $.615^{* * * *}(.173)$ & $.594^{* * * * *}(.172)$ & $.390^{*}(.175)$ \\
\hline Divorced, second year & $.761^{* * * *}(.158)$ & & $.748^{* * * *}(.159)$ & $.816^{* * *}(.170)$ & $.802^{* * * *}(.170)$ & $.600^{* * * *}(.173)$ \\
\hline Divorced, third year & $.474^{* *}(.165)$ & & $.496^{* * *}(.166)$ & $.404^{*}(.184)$ & $.369^{*}(.183)$ & $.179(.186)$ \\
\hline Divorced, four or more & & & & & & \\
\hline $\begin{array}{l}\text { years } \\
\text { (n) }\end{array}$ & $.995^{* * * *}(.122)$ & & $.956^{* * * *}(.123)$ & $.927^{* * * *}(.140)$ & $.897^{* * * * *}(.140)$ & $.702^{* * * * *}(.143)$ \\
\hline \multicolumn{7}{|l|}{$\begin{array}{l}\text { Cohabitation (reference: BMI } \\
\text { when living without a } \\
\text { partner) }\end{array}$} \\
\hline Cohabiting, first year & & $.376^{* * * *}(.079)$ & $.371^{* * * *}(.081)$ & $.241^{* * *}(.089)$ & $.235^{* * *}(.089)$ & $.171(.089)$ \\
\hline Cohabiting, second year & & $.419^{* * * * *}(.088)$ & $.414^{* * * * *}(.090)$ & $.342^{* * * *}(.097)$ & $.341^{* * * * *}(.096)$ & $.261^{* *}(.096)$ \\
\hline Cohabiting, third year & & $.649^{* * * *}(.090)$ & $.630^{* * * * *}(.093)$ & $.494^{* * * *}(.101)$ & $.480^{* * * * *}(.101)$ & $.374^{* * * *}(.101)$ \\
\hline \multicolumn{7}{|l|}{ Cohabiting, four or more } \\
\hline years & & $.732^{* * * *}(.061)$ & $.672^{* * * *}(.071)$ & $.563^{* * *}(.079)$ & $.570^{* * * * *}(.079)$ & $.460^{* * * *}(.079)$ \\
\hline Separated, one year & & $-.299^{* * *}(.092)$ & $-.279^{* * *}(.096)$ & $-.295^{* * *}(.106)$ & $-.258^{*}(.106)$ & $-.273^{* * *}(.106)$ \\
\hline Separated, two years & & $-.024(.098)$ & $-.007(.102)$ & $-.012(.108)$ & $-.011(.108)$ & $-.046(.107)$ \\
\hline Separated, three years & & $-.071(.102)$ & $-.065(.105)$ & $-.144(.110)$ & $-.104(.110)$ & $-.107(.109)$ \\
\hline Separated, four years & & $.022(.106)$ & $.037(.108)$ & $.071(.114)$ & $.076(.113)$ & $.060(.113)$ \\
\hline \multicolumn{7}{|l|}{ Weight-related behaviors } \\
\hline Smoking $(1=$ yes $)$ & & & & & $-.616^{* * * * *}(.046)$ & $-.539^{* * * *}(.046)$ \\
\hline Exercise & & & & & $-.028^{* *}(.011)$ & $-.024^{*}(.011)$ \\
\hline Eating & & & & & $-.180^{* * * * *}(.018)$ & $-.186^{* * * *}(.018)$ \\
\hline \multicolumn{7}{|l|}{ Control variables } \\
\hline Pregnant $(1=$ yes $)$ & & & & & & $1.390^{* * * *}(.107)$ \\
\hline Recent birth $(1=$ yes $)$ & & & & & & $.803^{* * * *}(.096)$ \\
\hline Having children $(1=$ yes $)$ & & & & & & $.403^{* * * *}(.097)$ \\
\hline $\begin{array}{l}\text { Employment: Transition } \\
\text { from not working to } \\
\text { working full-time }\end{array}$ & & & & & & \\
\hline$(1=$ yes $)$ & & & & & & $-.054(.042)$ \\
\hline $\begin{array}{l}\text { Employment: Transition } \\
\text { from not working to } \\
\text { working part-time }\end{array}$ & & & & & & \\
\hline$(1=$ yes $)$ & & & & & & $-.020(.035)$ \\
\hline Stress & & & & & & $-.009(.012)$ \\
\hline Health & & & & & & $-.064^{* * *}(.015)$ \\
\hline Constant & $24.755^{* * * * *}(.057)$ & $24.769^{* * * * *}(.049)$ & $24.441^{* * * * *}(.067)$ & $24.490^{* * * *}(.075)$ & $25.213^{* * * * *}(.094)$ & $25.359^{* * * * *}(.120)$ \\
\hline Observations & 41,059 & 41,059 & 41,059 & 35,729 & 35,729 & 35,629 \\
\hline
\end{tabular}

Note. Table 4 can be read as follows: To differentiate the effects of changes in marital versus cohabitation status, Model 1a (which includes only changes in marital status), Model $1 \mathrm{~b}$ (only changes in cohabitation status), and Model 2a are presented next to each other. Including changes in cohabitation and marital status in the same model makes it possible to estimate the effect of one while controlling for the other. For example, by comparing the beta values of Model 1a with Model 2a, one can see that the influence of getting married on BMI is clearly reduced when the effects of cohabitation are controlled (as is done in Model 2a). However, the effects of moving in together on BMI stay about the same when the effects of getting married are controlled Importantly, Model 2a includes all participants, whereas Model $2 \mathrm{~b}$ includes only participants for whom smoking, exercise, and eating were assessed. Due to the lower number of cases, only the results of Model $2 \mathrm{~b}$ can be directly compared with the results of Models 3 and 4 . Please note that despite diverging case numbers, Models 2a and 2b yield comparable results. Analogous comparisons can be made with Models 3 and 4 . Model 3 includes weight-related behaviors. Here, a negative beta shows that starting to smoke resulted in a lower BMI, to quit smoking lead to a higher BMI. Model 4 includes the control variables (i.e., children, change in employment status, stress, and health). BMI before first marriage is used as the reference BMI for the effects of both marriage and divorce on BMI. The same reference is used to make the effects of marriage and divorce comparable. However, the beta weights in Table 3 can be used to understand whether divorce leads to weight loss relative to post-marriage BMI (i.e., being married for four years or more): The beta-weight of "divorced, four or more years" (e.g., from Model 4) minus the beta-weight of "married, four or more years" shows the weight change; here, .702 $.220=.482$. The value is positive; this means that women have gained weight (increased their BMI by $.482 \mathrm{~kg} / \mathrm{m}^{2}$ ) after a divorce relative to their BMI after four years or more of being married. If the value was negative, they would have lost weight; if the value was zero, their weight would not have changed. Standard errors in parentheses. BMI $=$ body mass index.

${ }^{*} p<.05{ }^{* * *} p<.01 .^{* * * *} p<.001$. 
Model $2 \mathrm{~b}$ reports the same predictor variables as Model 2a, but only for those participants for whom data on weight-related behaviors are available. Thus, by comparing Model $2 \mathrm{a}$ and Model 2b, one can identify potential differences between the main sample and the subsample that reported weight-related behaviors; moreover, Model 2b and Model 3 can be compared directly. Model 4 additionally contains control variables that have often been ignored in previous research, namely, having children, changes in employment status, perceived stress, and subjective health.

\section{Results}

In both men and women, body weight was higher for cohabiting and married respondents than for those without a partner (see Table 2 for demographic characteristics). The multilevel estimates for BMI in men and women are presented in Tables 3 and 4 , respectively. Figure 1 presents the predicted changes in BMI by relationship transition, with all control variables included in the analyses.

\section{Effect of Relationship Transitions on Men's BMI}

Effects of marriage and divorce on BMI. When only the effects of marital status were considered (Table 3, Model 1a), both marriage and divorce led to significant weight gain in men. The longer the marriage lasted, the larger the weight increase: up to $0.833 \mathrm{~kg} / \mathrm{m}^{2}$ after four or more years. Analogous results emerged for the effects of divorce on weight gain relative to premarriage BMI $\left(+1.222 \mathrm{~kg} / \mathrm{m}^{2}\right.$ four or more years after divorce). Being divorced for four years or longer thus led to about $0.4 \mathrm{~kg} / \mathrm{m}^{2}$ more
A

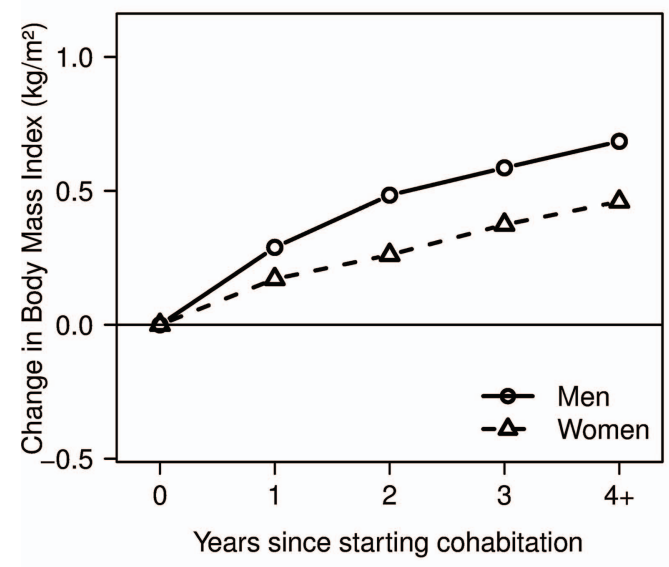

C

Separation

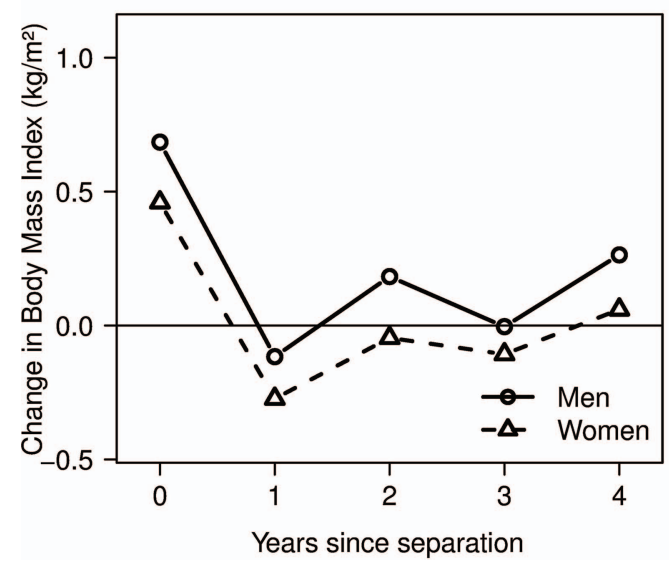

B

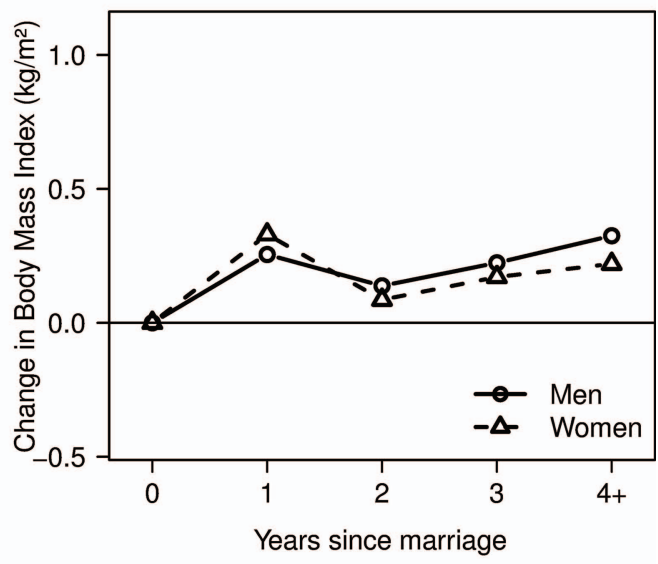

D

Divorce

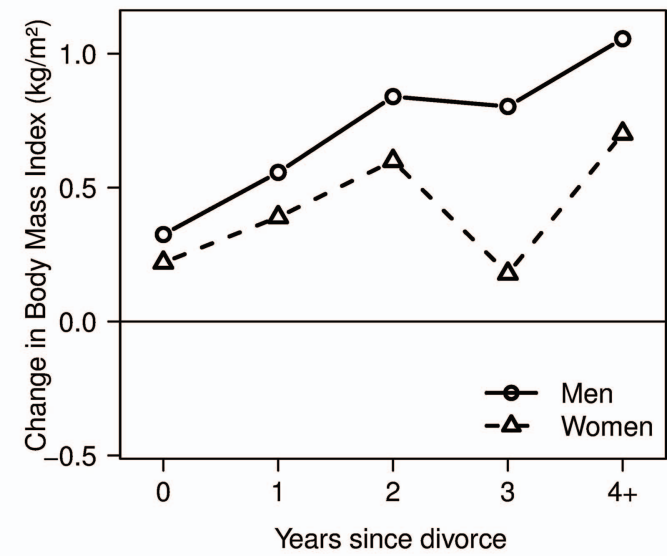

Figure 1. Predicted changes in BMI by relationship transitions (based on Model 4 in Tables 3 and 4). The " 0.0 " on the $y$-axis represents the reference point. For Figures A and C, the reference point is "weight when living without a partner"; for Figures B and D, the reference category is "weight before first marriage". The models presented in Figures A-D control for all other predictors: age, age-squared, weight-related health behaviors (smoking, exercise, and eating), children (pregnancy, recent birth, and having children), transitions in employment status, perceived stress, and subjective health. Figure A shows effects of cohabitation on BMI, additionally controlled for effects of marriage, separation, and divorce on BMI; Figure B shows effects of marriage on BMI, additionally controlled for effects of cohabitation, separation, and divorce. Figures C and D show analogous results for separation and divorce. 
weight gain than a marriage of the same duration (1.222 $0.833=0.389 \mathrm{~kg} / \mathrm{m}^{2}$ ).

Effects of cohabitation and separation on BMI. Moving in with a partner led to weight gain (Model 1b). The longer cohabitation lasted, the larger the effect on weight gain. In contrast, the BMI of men who had separated from their partner in the last three years did not differ significantly from their BMI prior to cohabitation. After four or more years' separation, a small weight gain of $0.229 \mathrm{~kg} / \mathrm{m}^{2}$ occurred.

Relative effects of relationship transitions. When both marital and cohabitation status were included in the analysis (Model 2a), the effects of cohabitation, separation, and divorce on BMI remained similar in size to those estimated by the models examining only marital (Model 1a) or cohabitation status (Model 1b). In contrast, the effects of marriage on BMI were significantly weaker in Model 2a than in 1a (e.g., married, first year: $t=10.25, p<$ $.001)$.

Weight-related behaviors. Model 2a includes all participating men; Model $2 b$, only those for whom data on weight-related behaviors were available. Importantly, in both models, the effects of marital and cohabitation status on BMI were comparable in direction and size. In Model 3, three weight-related behaviorssmoking, exercise, and healthy eating-were included. Although an increase in any of the three weight-related behaviors led to significant weight loss (from about $-0.046 \mathrm{~kg} / \mathrm{m}^{2}$ for exercise to $-0.312 \mathrm{~kg} / \mathrm{m}^{2}$ for smoking), and a decrease led to weight gain, including them in the model did not reduce the predictive value of marital or cohabitation status on BMI.

Control variables. Pregnancy, birth, and having children led to significant weight gain in men (about 0.3 to $0.4 \mathrm{~kg} / \mathrm{m}^{2}$; Model 4). Transitioning to a full-time job led to an increase in BMI. Changes in perceived stress or health were not related to BMI. Controlled for children, employment transitions, stress, and health, the sole effect of marriage and divorce was slightly reduced, but remained significant (exception: married, second year). Similarly, the effects of cohabitation and separation on BMI remained significant, albeit slightly smaller (exception: separated, second year no longer significantly predicted weight gain).

\section{Effect of Relationship Transitions on Women's BMI}

Effects of marriage and divorce on BMI. When only the effects of marital status were considered (Table 4, Model 1a), both marriage and divorce led to significant weight gain in women. Being divorced for four years or longer led to more weight gain than being married for four years or longer $(0.995-0.690=$ $0.305 \mathrm{~kg} / \mathrm{m}^{2}$ ).

Effects of cohabitation and separation on BMI. Moving in together also led to weight gain (Model 1b). The longer cohabitation lasted, the larger the effect on weight gain. In contrast to men, women lost significant weight in the first year after separating from their partner: on average, their BMI fell below the precohabitation BMI $\left(-0.299 \mathrm{~kg} / \mathrm{m}^{2}\right)$. When women had been separated for two years or more, their BMI did not differ significantly from their precohabitation BMI.

Relative effects of relationship transitions. Examining the effects of marital and cohabitation status in the same model (Model 2a) revealed comparable effects of cohabitation, separation, and divorce on BMI. The effects of marriage on weight gain were significantly weaker than when only marital status was used as predictor (Model 1a; e.g., married, first year $t=10.24, p<$ $.001)$.

Weight-related behaviors. Including smoking, exercise, and healthy eating in the analyses (Model 3) did not change the predictive value of marital or cohabitation status on weight change. However, an increase in any of these behaviors led to significant weight loss (from $-0.024 \mathrm{~kg} / \mathrm{m}^{2}$ for exercise to $-0.539 \mathrm{~kg} / \mathrm{m}^{2}$ for smoking), a decrease led to weight gain.

Control variables. Pregnancy, birth, and having children significantly predicted weight gain; not surprisingly, the coefficients were up to about five times larger than in men. Better subjective health predicted a lower BMI in women. Neither change in employment status nor perceived stress was related to changes in BMI. Controlling for the effects of children, employment, health, and stress (Model 4) weakened the effects of marriage and divorce on BMI. In fact, BMI in the second and third year of marriage was no longer significantly different from premarriage BMI. The effects of divorce and cohabitation on weight gain generally remained significant (except for cohabitation in the first year and divorce in the third year), albeit noticeably weaker. A recent separation still led to weight loss.

\section{Sex Effects of Relationship Transitions, Children on BMI}

To test for differences between men and women, we reran Models $2 \mathrm{a}$ and 4 (cf., Tables 3 and 4), this time including the interaction between sex, predictor variables, and control variables. There were generally no sex differences in the effects of relationship transitions on BMI, with the exception that women gained less weight than men three years after a divorce and four or more years into cohabitation (Model 4). Women gained more weight than men after a recent birth; however, this difference vanished by the time the child was 18 months or older. There were no sex differences in the effects of engaging in weightrelated behaviors on BMI, except that women who started smoking lost more weight than men doing the same. The only sex difference in the control variables assessed was that women transitioning to full-time employment gained less weight than men doing the same (see Table S2 in the online supplementary material).

\section{Effects of Relationship Transitions on BMI in First Marriages and Remarriages}

To test whether the observed patterns of BMI change after relationship transitions generalized to remarriages, all models were rerun including all participants who had ever been married, independently of how often (see Table S3 and Table S4 in the online supplementary material). When all marriages were considered, the effects on BMI of getting married and getting divorced were weaker in both men and women (see Table S3 and Table S4 in the online supplementary material). However, the effects of cohabitation and separation remained generally stable.

\section{Discussion}

Particularly in men, cohabitation was overall associated with much more pronounced and stable weight gain than was marriage 
(controlling for weight-related behaviors, age, children, employment, stress, and health). In women, this effect was most visible after longer cohabitation and marriage. BMI after separation was generally comparable to BMI before cohabitation; women lost some weight in the first year, men gained some weight after four or more years of separation. In contrast, divorce led to considerable weight gain over time, especially in men. Changes in weightrelated behaviors did not explain the distinct effects of cohabitation, marriage, separation, and divorce on BMI. The effect of relationship transitions on BMI was reduced but mostly held when controlling for the effects of children, changes in employment status, perceived stress, and subjective health. Pregnancy and children considerably increased BMI, and in women, better subjective health predicted lower BMI. These results are largely consistent with the marriage market hypothesis: Transitions into cohabitation and marriage were followed by weight gain. However, the weight gain after four or more years of cohabitation was much larger - in fact, double the size- of that occurring after four or more years of marriage.

This is one of the first longitudinal studies to compare the effects of cohabitation and marriage on BMI. Most studies examining how marriage affects BMI have not directly compared it with cohabitation (Dinour et al., 2012). This may have led to an overestimation of the effect of marriage on BMI. Why is cohabitation a stronger predictor of weight gain than marriage? One possible reason is chronological order. Cohabitation usually precedes marriage (e.g., married and cohabiting participants in this study were about 20 years older than never married cohabiting participants, see Table 2) and-given that most cohabiting couples eventually marry (Goodwin, Mosher, \& Chandra, 2010)—most of the weight change may occur during cohabitation.

Partly consistent with the marriage market hypothesis and its implication that people lose weight again after separation or divorce, respondents who separated generally showed BMIs similar to those they had when living alone. Again, the chronology of events (separation commonly precedes divorce) may explain why separation and divorce predict different changes in BMI. Separation from a partner is often associated with lower well-being (Ezzati, Martin, Skjold, Vander Hoorn, \& Murray, 2006), loss of appetite, and subsequent weight loss (American Psychiatric Association, 2013; see Wilcox et al., 2003). Importantly, the present findings showed weight gain in the wake of divorce. In fact, men gained more weight after their divorce than during their first marriage. The few previous studies examining weight change after divorce have reported mixed findings, potentially stemming from inconsistent control for the effects of cohabitation, a shorter postdivorce follow-up time, and not excluding participants who remarried (Dinour et al., 2012).

Changes in exercising, healthy eating, and smoking behavior did not account for changes in BMI after relationship transitions. Thus, the present findings contradict both the respective hypotheses formulated here and previous findings indicating that weightrelated behaviors change after cohabitation or marriage (Meyler, Stimpson, \& Peek, 2007); they do not support either the negative protection hypothesis or the marriage protection hypothesis. However, using a single item (as done here) to assess weight-related behaviors might make it more difficult to detect their influence on BMI. For example, cohabitation could increase the amount of calories consumed per meal (Sobal \& Rauschenbach, 2003) or the frequency of meals (Herman, 2015). Neither of these explanations was captured by the item used, which assessed the attention paid to healthy eating. Additionally, it is possible that the item in question measures an attitude rather than an actual behavior (e.g., Mata, Dallacker, Vogel, \& Hertwig, in press). However, other studies using similar items detected differences in physical activity between individuals who were married versus cohabiting (Rapp \& Schneider, 2013). Clearly, future studies need to probe a wider range of behavioral mechanisms that may underlie weight changes in the wake of relationship transitions.

This is the first longitudinal study in Germany to compare the effects of cohabitation and marital status on BMI. By analyzing within-person changes across time, it was possible to eliminate potentially confounding between-person factors. The analyses explicitly compared the effect of changes in marital status versus cohabitation status and showed that, overall, cohabitation has a stronger influence on BMI than marriage. This finding has important implications, suggesting that research that does not consider the influence of cohabitation on BMI is likely to overestimate the influence of marriage. Second, cohabitation has a substantially larger long-term influence on BMI than marriage does.

Going beyond previous research, this study also analyzed what transitions out of cohabitation and marriage mean for individuals' BMI. The timespan of 16 years made it possible to compare the effects of cohabitation with those of marriage. Lastly, the models included other factors contributing to weight gain that are frequently neglected, including children, employment status, perceived stress, and subjective health. The available data do not allow the role of alcohol consumption for changes in BMI after relationship transitions to be meaningfully explored. Future research should include this potentially relevant behavior.

One limitation of the study is that weight and height were self-reported, potentially leading to an underestimation of BMI (Gorber, Tremblay, Moher, \& Gorber, 2007). However, asking people to report height and weight in a face-to-face interview, as was done here, yields more accurate responses than, for example, do telephone interviews (Ezzati et al., 2006). Moreover, research with overweight participants has found the differences between self-reported weight and measured weight to be either insignificant or very small (Christian, King, Yanovski, Courcoulas, \& Belle, 2013). Importantly, this investigation focused on weight change within a person. Thus, even if there was systematic bias in selfreported weight, it is likely that it had a similar effect across time. Thus, bias in self-reported weight probably had little effect on the present results. A second limitation is that about a third of the original sample was excluded for theoretical or statistical reasons. Nevertheless, the original sample was almost identical to the final sample with regard to the variables of interest. Finally, the present results do not clarify how cohabitation and marriage led to weight gain. One possible mechanism can be excluded, however: The weight-related behaviors examined did not explain changes in weight above and beyond the influences of relationship transitions.

The present findings show that changes in people's relationship status affect their BMI. Transitioning to a shared life, especially moving in together, is associated with a significant increase in BMI, but so is leaving behind a shared life, especially divorce. These findings are important for several reasons. First, they qualify the view that living with a partner is invariably good for health. Rather, depending on a person's BMI prior to relationship transi- 
tions, relationship effects on BMI can either decrease or increase the risk of mortality (Aune et al., 2016). Second, divorcees do not return to their premarriage weight: Summing up the observed relationship effects on BMI from four years each of cohabitation, marriage, separation, and divorce (and controlling for weightrelated behaviors as well as children, change in employment status, stress, and health) reveals that men and women gained around 2.3 and $1.4 \mathrm{~kg} / \mathrm{m}^{2}$, respectively. For men of average height (about $180 \mathrm{~cm}$ ), this represents a difference of about $7.5 \mathrm{~kg}$. Given that $25 \%$ of unmarried, noncohabiting men in the current sample have a BMI of $27.0 \mathrm{~kg} / \mathrm{m}^{2}$ or higher, an increase of $2.3 \mathrm{~kg} / \mathrm{m}^{2}$ would increase their risk of all -cause mortality by up to about $13 \%$ (Aune et al., 2016). The present results suggest that transitions into and out of cohabitation or marriage are periods of special vulnerability for weight gain, and social factors contributing to weight gain are often overlooked (Vartanian, Herman, \& Wansink, 2008). Importantly, being married generally decreases mortality (Rendall, Weden, Favreault, \& Waldron, 2011). Being married and having a healthier BMI could additively decrease mortality and not only add years to life but life to years by decreasing morbidity and increasing quality of life. Of course, relationship transitions are one among many factors influencing BMI-but today's population levels of obesity do not afford the luxury of ignoring any contributing factor.

\section{References}

American Psychiatric Association. (2013). Diagnostic and Statistical Manual of Mental Disorders (5th ed.). Washington, DC: Author.

Aubin, H. J., Farley, A., Lycett, D., Lahmek, P., \& Aveyard, P. (2012). Weight gain in smokers after quitting cigarettes: Meta-analysis. BMJ: British Medical Journal, 345, e4439. http://dx.doi.org/10.1136/bmj .e4439

Aune, D., Sen, A., Prasad, M., Norat, T., Janszky, I., Tonstad, S., . . . Vatten, L. J. (2016). BMI and all cause mortality: Systematic review and non-linear dose-response meta-analysis of 230 cohort studies with 3.74 million deaths among 30.3 million participants. BMJ: British Medical Journal, 353, i2156. http://dx.doi.org/10.1136/bmj.i2156

Averett, S. L., Argys, L. M., \& Sorkin, J. (2013). In sickness and in health: An examination of relationship status and health using data from the Canadian National Public Health Survey. Review of Economics of the Household, 11, 599-633. http://dx.doi.org/10.1007/s11150-012-9143-z

Averett, S. L., Sikora, A., \& Argys, L. M. (2008). For better or worse: Relationship status and body mass index. Economics and Human Biology, 6, 330-349. http://dx.doi.org/10.1016/j.ehb.2008.07.003

Brennan, A., Ayers, S., Ahmed, H., \& Marshall-Lucette, S. (2007). A critical review of the Couvade syndrome: The pregnant male. Journal of Reproductive and Infant Psychology, 25, 173-189. http://dx.doi.org/10 $.1080 / 02646830701467207$

Bruederl, J., \& Ludwig, V. (2015). Fixed-effects panel regression. In H. Best \& C. Wolf (Eds.), The SAGE Handbook of Regression Analysis and Causal Inference (pp. 327-357). London, England: Sage.

Christakis, N. A., \& Fowler, J. H. (2007). The spread of obesity in a large social network over 32 years. The New England Journal of Medicine, 357, 370-379. http://dx.doi.org/10.1056/NEJMsa066082

Christian, N. J., King, W. C., Yanovski, S. Z., Courcoulas, A. P., \& Belle, S. H. (2013). Validity of self-reported weights following bariatric surgery. Journal of the American Medical Association, 310, 2454-2456. http://dx.doi.org/10.1001/jama.2013.281043

Gorber, S. C., Tremblay, M., Moher, D., \& Gorber, B. (2007). A comparison of direct vs. self-report measures for assessing height, weight and body mass index: A systematic review. Obesity Reviews, 8, 307-326. http://dx.doi.org/10.1111/j.1467-789X.2007.00347.x

Dinour, L., Leung, M. M., Tripicchio, G., Khan, S., \& Yeh, M.-C. (2012). The association between marital transitions, body mass index, and weight: A review of the literature. Journal of Obesity, 2012, 294974. http://dx.doi.org/10.1155/2012/294974

Ezzati, M., Martin, H., Skjold, S., Vander Hoorn, S., \& Murray, C. J. L. (2006). Trends in national and state-level obesity in the USA after correction for self-report bias: Analysis of health surveys. Journal of the Royal Society of Medicine, 99, 250-257. http://dx.doi.org/10.1177/ 014107680609900517

Fogelholm, M., Kujala, U., Kaprio, J., \& Sarna, S. (2000). Predictors of weight change in middle-aged and old men. Obesity Research, 8, 367373. http://dx.doi.org/10.1038/oby.2000.44

Gallo, L. C., Troxel, W. M., Matthews, K. A., \& Kuller, L. H. (2003) Marital status and quality in middle-aged women: Associations with levels and trajectories of cardiovascular risk factors. Health Psychology, 22, 453-463. http://dx.doi.org/10.1037/0278-6133.22.5.453

Goodwin, P. Y., Mosher, W. D., \& Chandra, A. (2010). Marriage and cohabitation in the United States: A statistical portrait based on cycle 6 (2002) of the National Survey of Family Growth. National Center for Health Statistics, Vital and Health Statistics, 23, 1-45.

Hartmann, C., Dohle, S., \& Siegrist, M. (2014). Time for change? Food choices in the transition to cohabitation and parenthood. Public Health Nutrition, 17, 2730-2739. http://dx.doi.org/10.1017/S13689800130 03297

Herman, C. P. (2015). The social facilitation of eating. A review. Appetite, 86, 61-73. http://dx.doi.org/10.1016/j.appet.2014.09.016

Horwitz, A. V., \& White, H. R. (1998). The relationship of cohabitation and mental health: A study of a young adult cohort. Journal of Marriage and the Family, 60, 505-514. http://dx.doi.org/10.2307/353865

Khan, C. M., Stephens, M. A. P., Franks, M. M., Rook, K. S., \& Salem, J. K. (2013). Influences of spousal support and control on diabetes management through physical activity. Health Psychology, 32, 739747. http://dx.doi.org/10.1037/a0028609

Kiecolt-Glaser, J. K., \& Newton, T. L. (2001). Marriage and health: His and hers. Psychological Bulletin, 127, 472-503. http://dx.doi.org/10 .1037/0033-2909.127.4.472

Kiefer, I., Rathmanner, T., \& Kunze, M. (2005). Eating and dieting differences in men and women. Journal of Men's Health \& Gender, 2, 194-201. http://dx.doi.org/10.1016/j.jmhg.2005.04.010

Klein, T., Rapp, I., \& Schneider, B. (2013). The influence of couples' living arrangements on smoking habits and body weight. Comparative Population Studies, 38, 673-694

Kohn, J. L., \& Averett, S. L. (2014). The effect of relationship status on health with dynamic health and persistent relationships. Journal of Health Economics, 36, 69-83. http://dx.doi.org/10.1016/j.jhealeco.2014 .03 .010

Kreider, R. M., \& Ellis, R. (2011). Number, Timing, and Duration of Marriages and Divorces, 2009. U.S. Department of Commerce, Economics and Statistics Administration, U.S. Census Bureau.

Kroh, M., Kühne, S., \& Siegers, R. (2017). Documentation of sample sizes and panel attrition in the German Socio-Economic Panel (SOEP) (1984 until 2015). SOEP Survey Papers 408: Series C. Berlin, Germany: DIW/SOEP

Lundborg, P., Nystedt, P., \& Lindgren, B. (2007). Getting ready for the marriage market? The association between divorce risks and investments in attractive body mass among married Europeans. Journal of Biosocial Science, 39, 531-544. http://dx.doi.org/10.1017/S0021932006001611

Marcussen, K. (2005). Explaining differences in mental health between married and cohabiting individuals. Social Psychology Quarterly, 68, 239-257. http://dx.doi.org/10.1177/019027250506800304

Mata, J., Dallacker, M., Vogel, T., \& Hertwig, R. (in press). The role of 
attitudes in diet, eating, and body weight. In D. Albarracín \& B. T. Johnson (Eds.). The Handbook of Attitudes: Vol. 2. Applications. New York, NY: Psychology Press.

Mata, J., Frank, R., \& Hertwig, R. (2015). Higher body mass index, less exercise, but healthier eating in married adults: Nine representative surveys across Europe. Social Science \& Medicine, 138, 119-127. http://dx.doi.org/10.1016/j.socscimed.2015.06.001

Meltzer, A. L., Novak, S. A., McNulty, J. K., Butler, E. A., \& Karney, B. R. (2013). Marital satisfaction predicts weight gain in early marriage. Health Psychology, 32, 824-827. http://dx.doi.org/10.1037/a0031593

Meyler, D., Stimpson, J. P., \& Peek, M. K. (2007). Health concordance within couples: A systematic review. Social Science \& Medicine, 64, 2297-2310. http://dx.doi.org/10.1016/j.socscimed.2007.02.007

Monsivais, P., Aggarwal, A., \& Drewnowski, A. (2014). Time spent on home food preparation and indicators of healthy eating. American Journal of Preventive Medicine, 47, 796-802. http://dx.doi.org/10.1016/j .amepre.2014.07.033

Musick, K., \& Bumpass, L. (2012). Re-examining the case for marriage: Union formation and changes in well-being. Journal of Marriage and Family, 74, 1-18. http://dx.doi.org/10.1111/j.1741-3737.2011.00873.x

Oliveira, A. J., Rostila, M., de Leon, A. P., \& Lopes, C. S. (2013). The influence of social relationships on obesity: Sex differences in a longitudinal study. Obesity, 21, 1540-1547. http://dx.doi.org/10.1002/oby .20286

Rapp, I., \& Schneider, B. (2013). The impacts of marriage, cohabitation and dating relationships on weekly self-reported physical activity in Germany: A 19-year longitudinal study. Social Science \& Medicine, 98, 197-203. http://dx.doi.org/10.1016/j.socscimed.2013.09.024

Raudenbush, S. W., \& Bryk, A. S. (2002). Hierarchical Linear Models. Applications and Data Analysis Methods (2nd ed.). Thousand Oaks, CA: Sage.
Rendall, M. S., Weden, M. M., Favreault, M. M., \& Waldron, H. (2011). The protective effect of marriage for survival: A review and update. Demography, 48, 481-506. http://dx.doi.org/10.1007/s13524-0110032-5

Sbarra, D. A., Law, R. W., \& Portley, R. M. (2011). Divorce and death: A meta-analysis and research agenda for clinical, social, and health psychology. Perspectives on Psychological Science, 6, 454-474. http://dx doi.org/10.1177/1745691611414724

Sobal, J., \& Rauschenbach, B. S. (2003). Gender, marital status, and body weight in older U.S. adults. Gender Issues, 21, 75-94. http://dx.doi.org/ 10.1007/s12147-003-0007-y

Vartanian, L. R., Herman, C. P., \& Wansink, B. (2008). Are we aware of the external factors that influence our food intake? Health Psychology, 27, 533-538. http://dx.doi.org/10.1037/0278-6133.27.5.533

Wagner, G. G., Frick, J. R., \& Schupp, J. (2007). The German SocioEconomic Panel Study (SOEP): Evolution, scope and enhancements Journal of Applied Social Science Studies, 127, 139-169.

Weeden, J., \& Sabini, J. (2005). Physical attractiveness and health in Western societies: A review. Psychological Bulletin, 131, 635-653. http://dx.doi.org/10.1037/0033-2909.131.5.635

Wilcox, S., Evenson, K. R., Aragaki, A., Wassertheil-Smoller, S., Mouton, C. P., \& Loevinger, B. L. (2003). The effects of widowhood on physical and mental health, health behaviors, and health outcomes: The Women's Health Initiative. Health Psychology, 22, 513-522. http://dx.doi.org/10 .1037/0278-6133.22.5.513

Received October 31, 2017

Revision received May 13, 2018

Accepted May 22, 2018 